\title{
Commentary on the special issue: anthropology and the labour theory of value
}

\author{
Fiona McCormack ${ }^{1}$ (D) \\ Published online: 8 March 2022 \\ (C) The Author(s), under exclusive licence to Springer Nature B.V. 2022
}

An anthropological revisiting of labour theories of value is timely, offering critical insights into specific local contradictions, the relationship of these to global capital accumulation, and the intrinsic historical unpredictability of these encounters (see also Angosto-Ferrandez and Presterudstuen 2016; Collins 2016, 2017; Hann 2018; Harvey, Krohn-Hansen and Wiley 2018; Narotzky 2018). The ethnographic possibilities explored in this collection - the cultural labour of locals in Venezuela and Chile, the "troubling excesses" (kinship, history, meaningfulness) that continue to plague Big Data production and the diverse aptitudes for sacrifice and risk found amongst Bitcoin miners - are, however, carefully balanced by the brute reality of material history as a matter of real hunger, real jobs and real dignity of control over labour, production and property and the very real differences in the political economic power to achieve or deny these values as well as control the form of production. These contributions delve deep into showing how the contemporary precarity of local actors producing novel commodities produces novel forms of inequality; an uneven development explored through the lives of smallholder famers in the Global South, Indigenous participants in tourism in South America and data miners globally. Indeed, uncovering hidden inequalities is a core thematic in this collection and one in which the concept of value rooted in labour theories is put to work; from this angle, value reveals the equivalences holding capitalist market exchanges together at the same time as it reveals the exact opposite, the inequality that emerges from equality (Henderson 2013). This duality is made explicit in the triumphalist call of Big Data, Bitcoin and eco-tourism entrepreneurs in the Global North, who proport to end world hunger or level the financial playing field, at the same time as, with a slight of hand, surplus value is extracted from producers and new forms of enclosures and private property continue to increase the gaps between "the haves and the have nots". Value, in this collection is not simply read as labour, but explicitly

Fiona McCormack

fio@waikato.ac.nz

1 Anthropology Programme, Te Wānanga O Ngā Kete/Division of Arts, Law, Psychology and Social Sciences, Te Kura Aronui/School of Social Sciences, University of Waikato, Private Bag 3105, Hamilton, New Zealand 
related to the material limits of a particular societal division of labour wherein relations of power are pivotal.

Angosto-Ferrández's critique of the tendency in recent anthropological scholarship to translate value as that which is desirable is insightful; separating meaning production from materially grounded social processes generates an analysis that reproduces notions of culture "that bind people and provide meaning to their actions through sets of organising principles that value would articulate" (see "the child that everyone has inside"). This tautology sidesteps an examination of cultural history and the contingent relationship between political economy, labour and inequality. Value, conceptualised as grounded in the social process of material production, is anthropologically significant in a world in which, as we are currently witnessing, "work" is being reorganised to differentiate between those most likely to suffer the pathology of COVID-19 and those able to accumulate savings while working from comfortable homes, a discrimination rooted historically in social divisions of labour.

Such a reading of value may also be applied to the precarious difference between indigeneity and assimilation. During the COVID-19 level four lockdowns ${ }^{1}$ in Aotearoa/New Zealand, two seemingly disparate questions emerged in fisheries: which category of person was permitted to fish from the shoreline and who would crew the large commercial vessels soon to be languishing in ports since national border closures had prevented the seasonal arrival of migrant workers. The first question appears to be concerned with subsistence fishing and the production of use value, whereas the latter points to the production of fish as exchange value. On deeper examination, though, both are rooted in the neoliberal reorganisation of New Zealand's fisheries in the late 1980s and an associated transformation of labour power. Crucially, this restructuring included a recognition of Indigenous fishing rights and their subsequent incorporation into New Zealand's nascent Individual Transferable Quota (ITQ) system. In the process, Māori fishing, which was simultaneously for use and exchange, was sliced into commercial and customary sectors. This transformation also impacted social organisation, in particular iwi (tribe), a conceptual category whose political power in the pre-colonial era ebbed and flowed, and $h a p \bar{u}$ (sub-tribe), the politically autonomous locus of tribal governance (Ballara 1998; Maaka 2003). Iwi were co-opted as state-mandated organisations early on in the colonial process, simultaneous with the disempowering of hap $\bar{u}$ and their leadership. This fundamental contradiction is of enduring significance and has taken on new dimensions in relation to the marine environment. In fisheries, $i w i$ were instated at the apex of a hierarchical kinship model, becoming the tribal recipients of fisheries settlement quota. The recent divisions and categorisation of labour underscore this revision - $i w i$ are associated with commercial fisheries, that is, the extraction of fish for profit, whereas hap $\bar{u}$ are linked with conservation, the preservation of fish stocks and fishing for designated cultural purposes (specifically tribal hui [meetings] and tangi [funerals]). Let us follow this thread a bit further, to see how, in line with what we find in other contributions to this special issue, these divisions take shape

\footnotetext{
$\overline{1}$ New Zealand introduced four levels of lockdown with four being the most restrictive.
} 
in tandem with new ideas about the world, reconceptualisations of nature and environments, and new forms of social organisation.

\section{Māori commercial fisheries: trade, property and cultural production}

As a mode of fisheries management, ITQs have been gaining ground in the Global North. This may be because their feasibility is best suited to wealthy countries which have the capacity for a high level of state involvement in the setting of Total Allowable Catches (a prerequisite for establishing ITQs and one which requires ongoing biological assessment of fish stocks) and administration (Fabinyi and Barclay 2022); a somewhat ironic turnabout given that ITQs are premised on 'rolling back the state' while enabling the market to govern access rights and quota trades as well as research (McCormack 2017). It is also the case, however, that environmental governance models are not neutral technical interventions; rather, they represent particular ideas about the world, based on valuations of people and the environment (Fabinyi and Barclay 2022). Mansfield (2011) argues that fisheries management is a highly politicised process wherein a culturally particular vision of nature is imposed along with a prescription for human participants: who should control it, how it should be used and who should benefit. In ITQ systems, hence, abstract labour is embedded in ideological notions of private property as the optimal way to incentivise ocean stewardship, the consolidation of fishing rights into fewer 'more efficient' user hands, market trade as a means of assuring equitable access and profit as the motivation for producing fish. Financialisation is also key. Wealth may be created simply by owning and exchanging quota enabling a profound separation of owners and producers.

Thirty years after the conversion of traditional fishing rights into ITQs and the growth of settlement assets, three distinct categories of Māori commercial fisheries have emerged: large fishing companies ${ }^{2}$ which strive to consolidate quota, establish vertically integrated companies and compete for the ability to lease quota from individual iwi; a few smaller companies which have collectivised the quota of a number of $i w i$ and seek to balance the tension between leasing quota and producing fish; and individual tribes who do not have the capital or resources required to establish fishing enterprises and instead lease their quota packages. The last group, the 'quota flickers, ${ }^{3}$ comprise the vast majority of the $58 \mathrm{iw} i$ who received fisheries settlement assets. There are identifiable dispossessions at work: wealth is now created through leasing quota rather than catching fish in the sea, a precarity that is particularly pronounced for coastal hap $\bar{u}$ who describe as minimal the annual dividends that trickle from leasing activities.

\footnotetext{
${ }^{2}$ Māori own three of the five largest fishing companies in New Zealand. Two of these are jointly owned by Māori (Aotearoa Fisheries Limited and Moana New Zealand, 50\% Māori owned) and one is fully owned (Ngai Tahu, 100\% Māori owned).

3 A term used by a research participant to describe the work of $i w i$ fishing companies.
} 
Long before COVID-19 border closures grounded fishing boats, Māori had been querying the disparity between their virtual (quota) and corporeal (labour) presence in the industry. Concern is relatively widespread and expressed by those involved at the iwi level of the industry as well as coastal hap $\bar{u}$, many of whom have been entirely excluded from commercial fisheries (McCormack 2021a, b). In my research project 'Iwi Settlement Quota and Māori fishing futures' (conducted 2017-2019), the CEO of an iwi fishing company lamented the industry-wide lack of 'our people' thirty years post settlement, an absence, he noted, that extended from fishing crew to upper managerial roles. An elder declared that commercial interests need to be infused with Māori values, culture and tikanga (custom/correct procedure), a former fisher questioned "what is actually Māori about Māori commercial fisheries"? And an environmental spokesperson from a coastal hapu requested that their affiliated $i w i$ freely gift or lease quota at affordable rates to encourage local livelihoods. These narratives correspond with 'revaluation projects', that is, they seek to draw attention to elements of the economy that have been obscured, recalibrate the system to recognise an important aspect or reconfigure parts of a societal division of labour that are unsustainable (Collins 2016). Value, in this analysis, is understood as "the necessary interrelationships amongst elements of any economic system" (Collins 2016: 109).

A systemic reliance on cheap migrant labour became apparent during New Zealand's first COVID-19 lockdown, as fishing companies tied up their deep-sea boats. In 2016, the industry had been forced to relinquish their use of foreign charter vessels following accusations of 'slave labour', the government extended New Zealand labour laws to migrant crew and fishing companies pledged to build capacity in the local labour force (Simmons and Stringer 2014). Nevertheless, in 2019 (preCOVID), $31 \%$ of the workforce in commercial fisheries was sourced from overseas, though in the deep sea sector, this figure was closer to $100 \%$ (Neilson 2021; Young 2021). The general New Zealand Merchant Service Guild ${ }^{4}$ insists that migrant crews continue to earn very low wages are hired as independent contractors rather than employees, come from third world supply countries and, despite planned as a transitional measure, a New Zealand workforce had never developed (Brown 2020). An industry stakeholder, meanwhile, opined "...there is major shortfalls in trained, skilled and drug-free Kiwis that will go to sea" (Allison" in Brown).

In exchange for allowing 570 Ukrainian and Russian crew to enter New Zealand's quarantine system ${ }^{6}$ through a critical workers exemption programme, the five largest New Zealand fishing companies signed an agreement to do more to attract, train and renumerate a local labour force. As noted in the introduction to this special issue, the spatial and temporal diversity in definitions of essential or critical worker has less to do with expressions of cultural diversity than the political character of the decision-making process behind such categorisation (see "the child that everyone

\footnotetext{
4 The Guild is a union representing maritime pilots, masters, deck officers, tug masters, launch masters and shore-based personnel who hold maritime qualifications and work in a supervisory capacity.

5 Independent Fisheries executive director, Mark Allison.

6 All people entering New Zealand were required to stay for 14 days in government Managed Isoloation Quarantine (MIQ) facilities.
} 
has inside"). Beyond the morality of extracting surplus value from local or global labour, however, is an equivalence-making incorporating humans and nature: the fish harvested by deep sea vessels are deemed 'low value species' where value refers to consumer preference or price. Such fish are semi-processed onboard and then reprocessed offshore into 'value added products' (Stringer et al. 2016). The separation between owner and producer noted above, thus, also has a spatial dimension: dislocated migrant labour is locked into the production of export-oriented fish.

\section{Customary use value}

The anthropology of fisheries has long held the relationship between fisher and fish to be of central concern, whether this be the alienated, extractive relation of capitalism (Carothers and Chambers 2012; Howard 2017; Pinkerton and Edwards 2009) or a bind that, in many ethnographic accounts of Indigenous fisheries, is reported as kin-like (Menzies 2016; Todd 2014). In Māori epistemologies, mindful of tribal variations, land and sea are perceived as continuous, an encompassment which extends to tribal ownership regimes. This linkage between environmental domains is also reflected in genealogical relationships between people, ancestors and non-human sea species (McCully and Mutu 2003). Kaitiaki (animal stewards such as stingrays, whales, sharks or other fish species), for instance, are understood to be shapeshifting ancestors, their appearance a harbinger of resource abundance or destruction and death as a result of ocean pollution or ritual transgression (Marsden and Henare 1992; Kawharu 2000). Kaitiaki are also politically mobilised in Indigenous claims to land, sea and resources (Kawharu 2000). Fishing activities are embedded in tikanga variously oriented towards reverence for gods, maintenance of resources, health and wellbeing as well as social control over users (Metge 1989); the intersection of these concerns results in a complex and rich ocean reality. Seafood remains a vital source of subsistence for coastal people and there is a palatable yearning for saltwater flavours. Coastal tribes are obligated to provide seafood at wider kin gatherings and, in the past, seafood was extensively gifted and traded (Firth 1929). Species decline is experienced as a generational loss of kin, knowledge, culture and food.

During New Zealand's first COVID lockdown in March 2020, all non-commercial fishing was prohibited as part of a larger requirement to 'stay at home'. Soon after, however, a call arose from prominent Māori community leaders that fishing be rendered an exception being crucial for contemporary subsistence purposes as well as cultural identity, particularly for island, coastal and rural Māori communities. In late August, the government acquiesced, permitting the exercise of Māori customary fishing rights. These rights were temporarily subject to social distancing rules and swimming, scuba diving, boating of any sort or motorised equipment was prohibited alongside any activity that might require search and rescue missions. ${ }^{7}$ However, two issues became apparent; first, what constituted customary fishing and, second, what category of person was a customary fisher. Indeed, the customary fishing

\footnotetext{
7 COVID-19 Public Health Response (Alert Level Requirements) Order (No 9) 2021, clause 16.
} 
rights permitted as an exception under level four lockdown rules do not resemble the formal Fisheries (Kaimoana Customary Fishing) Regulations 1998 developed out of the 1992 Crown settlement of Māori fisheries. As was the case with the use of migrant labour in commercial fisheries, the COVID-19 pandemic threw into relief the underlying contradictions that have emerged in the post-settlement era of Māori fisheries.

The formal legislation of customary tenures is double-edged, acknowledging Indigenous experiences and practices at the same time as rendering these recognisable by the state (Peterson and Rigsby 2014). In New Zealand, the shape of customary fisheries was formed in a dialectic with the privatisation and financialisation of commercial rights. Customary fisheries are premised on the identification of an exclusive tribal seascape (rohe moana) and the authorisation of local tangata kaitiaki (human environmental stewards) to provide fishing permits. These permits must specify species, quantity, date of harvesting and fishing area, the data from which feeds into calculations of total allowable catches. Crucially, permits are restricted to harvesting for the purposes of hui or tangi, a use value that is entirely ceremonial in nature. Trading, bartering, or the reciprocal exchange of customary harvested fish is expressly prohibited. These rules, however, have been variously interpreted over time and the number of hui (tribal meetings) for which customary permits that are requested has fluoresced. Locally experienced Māori fishers and divers are often called upon to supply fish; however, it is increasingly common for commercial vessels to harvest customary catch. Indeed, Māori fishing companies had already been fishing customary take during the level four lockdown and fish had been distributed to affiliated hapu and marae (meeting house complexes). This momentum is part of a longer trajectory wherein pattaka (traditionally store houses) have been conceptually revised by some Māori fishing companies into a system wherein commercial vessels catch customary permitted take which is then freely gifted to hapu and whānau (extended family) applicants. The process works to reconcile the separation of fish from the right to fish through temporary acts of giving; a post-settlement hybridisation that is understood as both an attempt to provision kin and as an agnostic gift exchange, a generous act that expresses a distorted social relation (Mauss 2002 [1950]). Furthermore, for commercial vessels, customary take provides a means through which bycatch (for which no quota is owned and for which penalties must be paid) can be offloaded.

The customary fishing rights exempted under level four lockdown rules do not exist in New Zealand's fisheries regulations. Rather, they imagine an Indigenous fishing right beyond the present regime by recognising subsistence production or fishing for a 'daily feed'. Such fishing is permitted under Fisheries (Amateur fishing) Regulations 2013 in which anyone, regardless of ethnicity or wealth, can fish subject to daily bag limits and/or species size. Hence, Māori subsistence fishers commonly operate (uneasily) under recreational rules, as do fishing clubs and competitions, charter boat operators and the sizable and influential recreational boating sector in New Zealand. Almost a year after Māori had been granted customary fishing exemptions in level four lockdowns, the decision was reversed and all New Zealanders, regardless of ethnicity, were permitted to fish from shore. This expansion arose as recreational fishers and oppositional parties argued (disingenuously) against 
special consideration for Māori, "viruses do not discriminate by race and neither should the law"8 (Te Ao Māori News 2021).

Drawing from the labour theory of value one can reveal the underlying inequivalences holding things together in this scenario: the migrant labour essential to the operation of commercial fisheries and the growing role of the commercial sector in harvesting Māori customary take. It also suggests the illusory naturalisation of exchange value as something which displaces use-value in the commodity form. Customary catch supplied by commercial vessels provision whānau (extended family) in need during COVID pandemic restrictions and contribute to a cultural significant food source at marae gatherings marking life events. Māori iwi involved in fisheries are engaged in a struggle to infuse cultural logics in their operations and hapu continue to request the fulfilment of reciprocal obligations regarding the distribution of quota and fish. Kinship connections, including with non-human species, challenge the oppositional positioning of Māori iwi and hapū in fisheries and Māori coalesce nationally when attempts are made to further enclose their marine spaces (McCormack 2021b). This dynamic, the internalised social contradictions and their inherent unpredictable social results, echoes the two-fold character of both labour and the value it produces remaining inherent in the commodity form despite the illusions of commodity fetishism (Webster 2016). It is this particular ambivalence that is the unpredictable but irrepressible resource for Māori resistance against assimilation to a neoliberal form of indigeneity.

\section{The labour theory of value and the special issue}

The articles in this special issue all understand the reorganisation of capital as essentially a social relation with both particular and universal features in specific locations. This is explicitly addressed in Angosto-Ferrández's article. In Arauncanía, Chile and Gran Sabana, Venezuela, the increasing participation of Indigenous populations in tourism development evokes a cultural phenomenon: the circulation of discursive representations of local environments as permanently inscribed with a particular form of collective labour. Property regimes importantly underly these expressions of 'cultural labour' stimulating a defetishization which ultimately reveals the concealment that pervades commodity fetishism. Tourism's growth, on one hand, is tied up with processes of enclosure, and on the other, articulates with local property rights and relations to provide opportunities for the assertion of Indigenous ways of knowing and Indigenous labour. This ethnographic insight echoes the hope in pro-poor and eco-tourism ventures and research that economically depressed regions can model tourism development to alleviate poverty, strengthen sovereignty and protect cultural and natural heritage sites. In Angosto-Ferrández's analysis, however, the evolution of cultural labour and commodity defestishization does not arise in response to formal tourism development, but rather, in spite of it.

\footnotetext{
${ }^{8}$ David Seymour, leader of New Zealand's right wing, liberal ACT political party.
} 
The tourism industry, like ITQ fisheries, is steeped in the institutional arrangements and ideologies of neoliberal governance. Critical scholars have pointed to the growth of market mechanisms in conservation and protected areas, significant sites of eco-tourism development (Büsher et. al 2012; West and Brockington 2006). In the case of large scale marine protected areas, for instance, a zoning logic prevails wherein the Exclusive Economic Zone is carved into spaces for maintaining unsustainable measures and others that strictly preserve it (Douvere 2008). This logic is also apparent in payment for ecosystem services, a method of monetarizing all matters, which while promising to break down the nature/culture distinction, turns everything into circuits of monetarization and accounting (Haraway 2016). Once nature becomes identified with this paradigm, it is seemingly logical to assume that an economic instrument is needed to correct what is constituted as a failure. Thus, the dominant theoretical stance for payment for ecosystem services is that ecosystem service degradation is the result of market failures to account for externalities, and that 'valuing' (desiring) and paying for such services will mitigate these effects (Kallis et al. 2013). This thesis is apparent in the association between large-scale protected areas and the perceived need to "create opportunities for additional targeted funding and innovative finance mechanisms" (Gjerde et. al. 2016). While traditional donors such as national governments, NGOs and private and institutional bodies are acknowledged as an important source of funding, protected areas are also, and increasingly, seen as sites where payment for ecosystem services mechanisms develop. In marine spaces this might include, for instance, financial instruments whereby taxes, fines and fees from shipping, extractive industries and energy producers are used to construct protected areas (Rogers and Laffoley 2011). Indeed, the creation of large-scale marine protected areas is seen to hinge on this model of finance (Costanza et. al. 2014).

Propertisation from above, whether through state and/or private mechanisms, provides a space where Indigenous actors in Arauncanía have challenged their dislocation. This occurs through local entrepreneurs engaging in a selective undoing of historical processes of land enclosures and commodification which had long alienated them from their territory. In Gran Sabana, where land is informally understood as commonly owned, locals involved in tourism engage in enclosures from below: a form of land grabbing that, as with all impositions of new property regimes, rewards some while displacing others, generating new class structures in the process (Hann 1998). This mobilisation of subaltern property rights and relations underlies the ability of Indigenous actors in both locations to appeal to cultural labour - a type of labour perceived as constitutive of natural environments that are transformed into consumable spaces through tourist ventures. In Angosto-Ferrández's analysis, this labour prevents the touristic gaze separating environments from the people who are associated with them; an effective recombination of nature and culture, a defetishization.

In 'Big Data won't feed the world' Giles and Stead describe how Big Data is reified by giant agribusinesses as an environmental and social fix with stakeholders claiming that it enables companies to track the growing uncertainties of climate indexes and corresponding agricultural yields. The authors show, however, how Big Data virtually and geographically extends the reach of novel forms of capitalism 
such that a new developmental axis is emerging differentiating the Global North and South. Furthermore, while climate change and increasing environmental crisis events undermine the prospects of agriculture around the world, data is a growth industry; a form of digital colonialism representing the integration of surveillance technologies into our daily lives. These developments portend a significant structural reorganisation of labour, value and control.

Building on the work of critical scholars who identify a nascent digital accumulation by dispossession or data grab, Giles and Stead argue more broadly that Big Data signifies "new modes of informational production and concomitant configurations of stakeholders that render novel digital labours productive of surplus value". Herein, agricultural data is the new commodity, displacing both land and agricultural products. The labour being extracted is represented by farmers on their smart phones who gift their local knowledge to agri-companies who then enclose it in new ways, moving it along a chain of valorisation to be rendered a commodity. Data, like fishing quota, is at once abstracted from that which is produced at the same time as it becomes an intangible vehicle for generating wealth. In this process, Indigenous epistemologies and generational experiences of place are flattened and concealed while immaterial labour and digital capitalism are ascendant.

Big Data is aligned with the institutions and ideologies of green growth, including market environmentalism and payment for ecosystem services; projects which engage in equivalence making of capital, people and nature. Read politically, the green revolution offers a technical fix for hunger under capitalism while functioning to dispossess people in the Global South. This is colonialism in a new guise as subalterns are rendered lacking in knowledge, capacity and skill, their very smallness quantifying their exploitation by Big Data's stakeholders. The technocentric discourse in which Big Data is immersed, however, is built on ontologically unstable phenomenon, reflecting the mutation of capitalist value itself. The free or generalised unpaid labour on which the whole enterprise rests must continually supress the messy reality of kinship, history, nature, culture and the meaningfulness and politics of food systems.

Extracting free or generalised unpaid labour is also revealed by Tremčinský to underlie the production of cryptocurrencies such as bitcoin. In this instance, however, it is seemingly unproductive labour or leisure which is harnessed, a creeping extension of capitalism into more and more areas of life vital for social reproduction. This concealment is vividly portrayed by the image of the artist endowed in a thermoelectric bodysuit harvesting his body temperature to mine digital money. In his analysis, Tremčinský puts the labour theory of value into play with Negri's scholarship on value as an effect of political control. This is a provocative bookending whereby value both reorganises reproductive labour and emerges as the ultimate source of control over individual bodies, a differential embedded in abstract labour power. For cryptocurrency participants, the very real subsumption of society to capital belies opportunities for engaging in the diversity of lived experiences which have been found to challenge this totality in the anthropological record. Bitcoin, Tremčinský astutely comments, returns social labour back to the modern factory.

Tremčinský's data is drawn from research on Bitcoin communities in the Czech Republic and Slovakia, members of whom are described as young, mostly 
cosmopolitan males enthralled with the Austrian school of economics. Hence, the state is conceived as an impediment to free market operations and individuals are deemed solely responsible for their own wellbeing. Property, in bitcoin's digital peer-to-peer network, appears as a distorted version of common property wherein the social relations and cooperation underpinning classic descriptions are all but negated (see Thompson 1993). Nobody owns 'the bitcoin'; people can only own specific bitcoins, but each owner is a methodological individual, that is, social phenomena is constructed as resulting entirely from individual motives and actions. Miners, for instance, compete with each other for the reward of bitcoins. Hardin's (1968) interpretation of the commons as inevitably subject to tragedy as individual users exploit common resources until they are depleted, is appropriate here. While the flaws in Hardin's account are well recorded in social science literature (Berkes 2009), including the misidentification of common property as private property writ large, the artificial construction of common property regimes (such as Māori customary marine tenure or bitcoin pools) often align with Hardin's original observations. That is, the discursive use of 'the commons' in Bitcoin's means of production seeks to conceal the structural features driving the individualisation of land, nature and even consciousness.

Surveillance technologies feature in Bitcoin production as each miner is subject to proof-of-work mechanisms and digital fingerprints, or hash functions. Hash functions are also tied to computational power and the growing inequality within miners (early and newcomers, farmers and pools) and between miners and investors. Underlying the production of cryptocurrencies is a massive consumption of energy, and one that is set to grow as labour intensifies. This, in the parlance of Hardin, is the real tragedy of the commons.

The articles in this collection demonstrate that interpreting the ethnographic presence through the lens of the labour theory of value has significant purchase. In each case study, the inequalities holding things together are critically revealed while collectively, the articles suggest an underlying logic to the way capitalist accumulation and surplus value extraction operate at different scales. These insights are especially important as we struggle through different stages of a global pandemic in what appears to be a non-predictable and non-linear way. The fact that "work" has emerged as central to health outcomes at the same time as becoming a point of resistance to late capitalism's total reach, provides anthropologists with new impetus to study local ways of life, meaning-making and hidden forms of inequality.

\section{References}

Angosto-Ferrandez, Luis Fernando, and Geir Henning Presterudstuen. 2016. Anthropologies of value. London: Pluto Press.

Ballara, Angela. 1998. Iwi: the dynamics of Māori tribal organisation from c. 1769 to c. 1945 . Wellington: Victoria University Press.

Berkes, Fikret. 2009. Revising the commons paradigm. Journal of Natural Resources Policy Research 1 (3): 261-264. 
Brown, Tim. 2020. Fishing companies accused of favouring foreign crews over qualified New Zealanders. Newshub 28 October 2020. https://www.newshub.co.nz/home/new-zealand/2020/10/fishing-compa nies-accused-of-favouring-foreign-crews-over-qualified-new-zealanders.html

Büscher, Bram, Sian Sullivan, Katja Neves, Jim Igoe, and Dan Brockington. 2012. Towards a synthesized critique of neoliberal biodiversity conservation. Capitalism Nature Socialism 23 (2): 4-30.

Carothers, Courtney, and Catherine Chambers. 2012. Fisheries privatization and the remaking of fishery systems. Environment and Society 3 (1): 39-59.

Collins, Jane L. 2016. Expanding the labor theory of value. Dialectical Anthropology 40 (2): 103-123.

Collins, Jane L. 2017. The politics of value. University of Chicago Press.

Costanza, Robert, Rudolf De Groot, Paul Sutton, Sander Van der Ploeg, Sharolyn J. Anderson, Ida Kubiszewski, Stephen Farber, and R. Kerry Turner. 2014. Changes in the global value of ecosystem services. Global Environmental Change 26: 152-158.

Douvere, Fanny. 2008. The importance of marine spatial planning in advancing ecosystem-based sea use management. Marine Policy 32 (5): 762-771.

Fabinyi, Michael and Kate Barclay. 2022. Asia-Pacific fishing livelihoods. Cham, Switzerland: Springer Nature.

Firth, Raymond. 1929. Primitive economics of the New Zealand Māori (1 ${ }^{\text {st }}$ Edition). Routledge and Sons Limited.

Gjerde, Kristina, Lora Reeve, Harriet Harden-Davies, Jeff Ardron, Ryan Dolan, Carole Durussel, Sylvia Earle, et al. 2016. Protecting earth's last conservation frontier: Scientific, management and legal priorities for MPAs beyond national boundaries. Research Online: University of Wollongong.

Hann, Chris. 1998. Introduction: the embeddedness of property. In Property relations: Renewing the anthropological tradition, ed. Chris Hann, 1-47. Cambridge University Press.

Hann, Chris. 2018. Economic anthropology. The international encyclopaedia of anthropology, 1-16.

Haraway, Donna. 2016. Anthropologists are talking-about the Anthropocene. Ethnos 81 (3): 535-564.

Hardin, Garret. 1968. The tragedy of the commons: The population problem has no technical solution; it requires a fundamental extension in morality. Science 162 (3859): 1243-1248.

Harvey, Penelope, Christian Krohn-Hansen, and John Wiley (Eds.). 2018. Dislocating labour: anthropological reconfigurations. John Wiley \& Sons.

Henderson, George. 2013. Value in Marx: The persistence of value in a more-than-capitalist world. University of Minnesota Press.

Howard, Penny McCall. 2017. Environment, labour and capitalism at sea: 'working the ground' in Scotland. Manchester University Press.

Kallis, Giorgos, Erik Gómez-Baggethun, and Christos Zografos. 2013. To value or not to value? That is Not the Question Ecological Economics 94: 97-105.

Kawharu, Merata. 2000. Kaitiakitanga: A Māori anthropological perspective of the Māori socio-environmental ethic of resource management. The Journal of the Polynesian Society 109 (4): 349-370.

Maaka, Roger. 2003. Perceptions, conceptions and realities: a study of the tribe in Maori society in the twentieth century. PhD Thesis. University of Canterbury, New Zealand.

Mansfield, Becky. 2011. "Modern industrial fisheries and the crisis of overfishing" in Political Ecology, ed. Richard Peet, Paul Robbins and Michael Watts, 84-99. London: Routledge.

Marsden, Maori and Te Aroha Henare. 1992. Kaitiakitanga: a definitive introduction to the holistic worldview of the Māori. Wellington, New Zealand: Ministry for the Environment.

Mauss, Marcel. 2002. The gift: The form and reason for exchange in archaic societies. Routledge.

McCormack, Fiona. 2017. Private oceans: The enclosure and marketisation of the seas. London: Pluto Press.

McCormack, Fiona. 2021a. Interdependent Kin in Māori Marine Environments. Oceania 91 (2): 197-215.

McCormack, Fiona. 2021b. The Kermadec Ocean Sanctuary: Terraqueous territorialization and Māori Marine Environments. Pacific Affairs 94 (1): 77-96.

McCully, Maitu and Margaret Mutu. 2003. Te Whā nau Moana: Ngā kaupapa me ngā tikanga: Customs and Protocols/ the teachings of McCully Matiu kaumatua rangatira of Te Whanau Moana and Ngati Kahu as told to Margaret Mutu. Auckland, New Zealand: Reed.

Menzies, Charles R. 2016. People of the saltwater: An ethnography of git lax m'oon. University of Nebraska Press.

Metge, Joan. 1989. Evidence of Alice Joan Metge in respect of Te Wharo Oneroa A Tohe. Submission to the Waitangi Tribunal Muriwhenua Land Report 1992, Wai 45 H/C 20. 
Narotzky, Susana. 2018. Rethinking the concept of labour. Journal of the Royal Anthropological Institute 24 (S1): 29-43.

Te Ao Māori News. 2021. Level 4 fishing rules changed, clearing up confusion. 29 August 2021. https:// www.teaomaori.news/level-4-fishing-rules-changed-clearing-confusion

Nielson, Michael. 2021. Government launches migrant labour inquiry in seafood industry to boost Kiwi jobs. New Zealand Herald 2 July 2021. https://www.nzherald.co.nz/nz/government-launches-migra nt-labour-inquiry-in-seafood-industry-to-boost-kiwi-jobs/OJAYTF6L7IOV4XQF7HEBWLY3D4/

Peterson, Nicolas, and Bruce Rigsby, eds. 2014. Customary marine tenure in Australia. Sydney University Press.

Pinkerton, Evelyn, and Danielle N. Edwards. 2009. The elephant in the room: The hidden costs of leasing individual transferable fishing quotas. Marine Policy 33 (4): 707-713.

Rogers, Alex, and Daniel d'Auvergne Laffoley. 2011. International earth system expert workshop on ocean stresses and impacts: summary workshop report. DIANE Publishing.

Simmons, Glenn, and Christina Stringer. 2014. New Zealand's fisheries management system: Forced labour an ignored or overlooked dimension? Marine Policy 50: 74-80.

Stringer, Christina, D. Steve Hughes, Hugh Whittaker, Nigel Haworth, and Glenn Simmons. 2016. Labour standards and regulation in global value chains: The case of the New Zealand fishing industry. Environment and Planning a: Economy and Space 48 (10): 1910-1927.

Thompson, Edward Palmer. 1993. Customs in common: studies in traditional popular culture. New Press/ORIM.

Todd, Zoe. 2014. Fish pluralities: Human-animal relations and sites of engagement in Paulatuuq. Arctic Canada. Études/inuit/studies 38 (1-2): 217-238.

Webster, Steve. 2016. Māori Indigeneity and commodity fetishism. Sites: a journal of social anthropology and cultural studies 13(2): 1-18.

West, Paige, and Dan Brockington. 2006. An anthropological perspective on some unexpected consequences of protected areas. Conservation Biology 20 (3): 609-616.

Young, Conan. 2021. Fishing companies stick with plan to bring in foreign crew. Radio New Zealand, 17 May 2021.https://www.rnz.co.nz/news/national/442705/fishing-companies-stick-with-plans-tobring-in-foreign-crews

Publisher's note Springer Nature remains neutral with regard to jurisdictional claims in published maps and institutional affiliations. 